\title{
Heinz Schilling, Martin Luther. Rebell in einer Zeit des Umbruchs
}

München : Beck, 2012, 714 p., 29,95€

\section{Gérald Chaix}

\section{(2) OpenEdition}

\section{Journals}

Édition électronique

URL : http://journals.openedition.org/ifha/8199

DOI : 10.4000/ifha.8199

ISSN : 2198-8943

Éditeur

IFRA - Institut franco-allemand (sciences historiques et sociales)

Référence électronique

Gérald Chaix, "Heinz Schilling, Martin Luther. Rebell in einer Zeit des Umbruchs », Revue de l'IFHA [En ligne], Date de recension, mis en ligne le 14 avril 2015, consulté le 22 septembre 2020. URL : http:// journals.openedition.org/ifha/8199; DOI : https://doi.org/10.4000/ifha.8199

Ce document a été généré automatiquement le 22 septembre 2020.

(CIFHA 


\section{Heinz Schilling, Martin Luther. Rebell in einer Zeit des Umbruchs}

München : Beck, 2012, 714 p., 29,95€

\section{Gérald Chaix}

On commémorera en 2017 le cinquième centenaire de l'affichage des 95 thèses de Luther. Les grandes manœuvres ont commencé. Infatigable, Heinz Schilling a pris une longueur d'avance en publiant, dès 2012, une imposante biographie consacrée au réformateur présenté comme un rebelle et replacé dans une époque qualifiée de bouleversement. L'auteur distingue trois moments : celui de l'enfance, des études et des premières années de vie monastique (1483-1511); celui de l'installation à Wittenberg et des débuts de la Réforme (1511-1525); enfin, de 1525 à 1546, celui marqué par une certitude prophétique et des échecs temporels. Les lecteurs familiers des nombreux articles et ouvrages de l'auteur retrouveront des thèmes déjà développés antérieurement, notamment dans Die neue Zeit. Vom Christeneuropa zum Europa der Staaten (1999). Il en est ainsi des six traits caractérisant le XVe siècle finissant: la recomposition des espaces (explorations maritimes, fragmentation de la chrétienté latine et impact de l'expansion ottomane), le développement de nouvelles formes de piété (sous l'influence de l'humanisme et de la devotio moderna), la territorialisation de l'Église universelle et la modernisation de la papauté, l'affirmation des États modernes, la croissance démographique et l'essor du capitalisme marchand, la vitalité des arts et des lettres (Renaissance et Humanisme), enfin, le profond sentiment d'insécurité dont témoignent aussi bien dévotion mariale, confréries et pèlerinages, que pogroms et anticléricalisme. Il en va de même pour le monde nouveau qui, fortement façonné par la pensée de Luther, s'impose moins d'un siècle plus tard : encore défendu par Charles Quint et Luther, l'universalisme touche à sa fin, le monde chrétien s'est définitivement fragmenté, l'Empire s'est territorialisé et le pouvoir de la papauté a été irrémédiablement ébranlé. Certes, la religion reste le ciment de la société, mais la doctrine de Luther porte en elle, selon H. Schilling, l'autonomisation du politique, le pluralisme (à commencer bien sûr par le pluralisme confessionnel) et la liberté de conscience. 
C'est la focalisation sur la personne de Luther qui fait tout l'intérêt de l'ouvrage. On y observe une impressionnante connaissance aussi bien de l'œuvre foisonnante du réformateur que de l'immense littérature secondaire qui lui est consacrée. On constate également la capacité de l'auteur à faire varier ses échelles d'analyse et à passer de l'approche macrohistorique qui lui est familière à une étude microhistorique qui, sous la forme d'une biographie, est pour lui une nouveauté. Les étapes de la première partie de la vie de Martin Luder sont clairement rappelées : la naissance dans une famille en pleine ascension économique et sociale (et donc pour le père le souhait de faire de son fils un juriste) ; une formation chez les Frères de la vie commune qui débouche sur une immatriculation à l'université d'Erfurt au printemps 1501. Les cours du semestre d'été ont à peine commencé que Martin décide de rejoindre le couvent des ermites de saint Augustin et de s'inscrire en théologie, rompant ainsi avec le projet paternel. Moine, il est ordonné prêtre en avril 1507. Universitaire, il enseigne à Wittenberg à partir de 1508, y obtient son doctorat en théologie en octobre 1512 et y fait toute sa carrière. La seconde période est pareillement bien scandée. Elle débute par le rappel de l'environnement - favorable - dont le talentueux professeur de théologie bénéficie dans la jeune université de l'électorat de Saxe. Elle se poursuit par cette "libération » qu'expriment théologiquement l'affirmation du salut par la grâce et symboliquement la publication des 95 thèses, le 31 octobre 1517. Luder devient Luther (le libre, du grec eleutheros). Elle se continue par la genèse du réformateur qui s'affirme face à l'Église (formulant et précisant sa pensée tout au long de l'année 1520), face à l'empereur (diète de Worms, avril 1521) et finalement face à l'Empire (bénéficiant du soutien indéfectible du prince-électeur de Saxe). Elle marque le début d'une activité forcenée, démultipliée par l'extraordinaire diffusion des libelles, des livres - en latin et en langue vernaculaire - et des images : comme traducteur de la Bible, comme théologien, comme prédicateur et comme organisateur, souvent contesté (Karlstadt, guerre des paysans, Müntzer), du mouvement réformateur. Elle s'achève par l'abandon du froc (octobre 1524) et le mariage avec Katharina von Bora (juin 1525). L'auteur accorde une large place à la troisième période. Elle est marquée par la transformation de l'Église et de la société au nom de l'Évangile, à Wittenberg et en Saxe. La Réforme luthérienne concerne désormais tout l'Empire et même toute l'Europe, en raison de l'affrontement avec la papauté et de la diffusion des idées luthériennes. Mais c'est aussi pour un Luther accablé de tâches et à la santé chancelante une période de tensions entre vie familiale, cercles d'amis, pratique de la musique, angoisses apocalyptiques et attentes eschatologiques (à l'aune desquelles il faut lire les écrits sur les Turcs et sur les Juifs). Elle s'achève dans la nuit du 17 au 18 février 1546 par une mort attendue, préparée et volontairement édifiante. Au-delà de laquelle se prolonge, se réalise et s'approfondit l'enseignement de Luther.

\section{INDEX}

Index chronologique : Période moderne

Thèmes : Histoire religieuse 
AUTEUR

GÉRALD CHAIX

Université de Tours 